\title{
Influência dos defeitos de solidificação na resistência à corrosão do Zamac 5 obtido por injeção sob pressão
}

\author{
Influence of the Solidification Defects on the \\ Corrosion Resistance of Zamac 5 Obtained \\ by Squeeze Casting
}

\author{
Luciane Thaís Fuhr ${ }^{1}$, Ana Caroline Viero Bianchin ${ }^{2}$, \\ Felipe Dalla Vecchia ${ }^{3}$, Fernando Dal Pont Morisso ${ }^{1,2}$, \\ Ângela Beatrice Dewes Moura ${ }^{1}$, Ricardo Martins de Martins ${ }^{1}$, \\ Carlos Leonardo Pandolfo Carone ${ }^{1,2}$, Sandra Raquel Kunst ${ }^{1}$, \\ Cláudia Trindade Oliveira ${ }^{1,2}$
}

\footnotetext{
${ }^{1}$ Instituto Ciências Criativas e Tecnológicas, Universidade FEEVALE. Novo Hamburgo, RS, Brasil.

${ }^{2}$ Programa de Pós-Graduação Profissional em Tecnologia de Materiais e Processos Industriais, Universidade FEEVALE, Novo Hamburgo, RS, Brasil.

e-mails: luciane.fuhr@gmail.com, angelab@feevale.br, ricardomartins@feevale.br, anacbianchin@hotmail.com, morisso@feevale.br, carloscarone@feevale.br, tessaro.sandra@gmail.com cto@feevale.br.

${ }^{3}$ Instituto do Petróleo e dos Recursos Naturais da PUCRS - Pontifícia Universidade Católica do Rio Grande do Sul, Porto Alegre, RS, Brasil.

e-mails: felipe.vecchia@pucrs.br
}

\section{RESUMO}

Metais sanitários são objetos que, segundo as exigências vigentes do mercado consumidor, devem ser, ao mesmo tempo, resistentes à corrosão e bonitos, com aspecto espelhado brilhante. Estes são geralmente produzidos em latão fundido devido às suas características de fácil processamento e eletrodeposição. No entanto, para reduzir custos de produção, o latão tem sido substituído por ligas de zinco na fabricação destes componentes. O Zamac possui propriedades como baixo ponto de fusão em comparação ao latão, o que permite a obtenção de peças de paredes finas e geometrias complexas. A injeção sob pressão para obtenção de peças de ligas hipoeutéticas de zinco (Zamac 5) permite maior produtividade associada a melhores características dimensionais, com custo cerca de $30 \%$ menor do que o do latão. Este estudo apresenta a caracterização macro e microestrutural do Zamac 5 injetado sob pressão, relacionando-as com a resistência à corrosão da liga. Para tanto, foram realizados ensaios de névoa salina e análises por meio de microscopia eletrônica de varredura, ensaios de microdureza e ensaios eletroquímicos de corrosão. O Zamac 5 injetado sob pressão apresentou corrosão não-uniforme em regiões distintas da peça quando submetido à atmosfera agressiva. Os resultados também mostraram que este fato está associado aos defeitos de porosidade oriundos do processo de fabricação da liga. A microdureza da liga foi associada também aos defeitos oriundos do processo de fabricação. Por fim, evidenciou-se que o comportamento eletroquímico da liga é pouco influenciado pela presença dos defeitos.

Palavras-chave: Zamac 5, injeção sob pressão, defeitos de porosidade.

\section{ABSTRACT}

Sanitary metals are objects that, according to the current requirements of the consumer market, must be both corrosion resistant and beautiful, with a shiny mirror appearance. These are usually produced in cast brass because of their easy processing and electrodeposition characteristics. However, to reduce production costs, brass has been replaced by zinc alloys in the manufacture of these components. Zamac has properties such as low melting point compared to brass, which allows the production of thin-walled parts and complex geometries. Pressure injection to obtain zinc hypoeutec alloys (Zamac 5) allows higher productivity associated with better dimensional characteristics, costing about $30 \%$ less than brass. This study presents the macro and microstructural characterization of Zamac 5 injected under pressure, relating them to the corrosion resistance of the alloy. For this, saline fog tests and analyzes were performed by scanning electron microscopy, microhardness tests and 
electrochemical corrosion tests. The Zamac 5 injected under pressure presented non-uniform corrosion in distinct regions of the part when subjected to the aggressive atmosphere. The results also showed that this fact is associated with porosity defects from the alloy manufacturing process. The microhardness of the alloy was also associated with defects from the manufacturing process. Finally, it was evidenced that the electrochemical behavior of the alloy is little influenced by the presence of the defects.

Keywords: Zamak 5, squeeze casting, porosity defects.

\section{INTRODUÇÃO}

Ligas de zinco contendo alumínio, cobre e magnésio (Zamac) como elementos de liga são potenciais substitutas para diversos materiais como os bronzes, com destaque para a área de engenharia [1,2], em especial para metais sanitários. Além disso, as ligas de zinco podem ser processadas por meio de diversos tipos de sistemas: vazamento, forjamento, extrusão e injeção, tanto por centrifugação quanto sob pressão. As ligas de zinco utilizadas comercialmente para injeção são chamadas de Zamac. O nome da série Zamac vem da abreviatura dos nomes dos elementos que as compõe: zinco, alumínio, magnésio e cobre. Tratam-se de ligas hipoeutetóides de zinco, com teores de alumínio em torno de 4\%, identificadas por números, por exemplo Zamac 3 e Zamac 5 de acordo com sua composição. As composições típicas das ligas de Zamac comumente comercializadas. Sua grande diversidade de aplicações deve-se à grande facilidade de processamento, pois possuem baixo ponto de fusão (em torno de $385^{\circ} \mathrm{C}$ ) e boa fluidez. Devido à presença do alumínio, permite a obtenção de peças de dimensões complexas com paredes finas, representando uma economia de material. O Zamac, contudo, é uma liga metálica mais frágil à corrosão em relação ao latão, material tradicionalmente utilizado em metais sanitários, e muito deve-se às imperfeições da matriz metálica inerentes ao próprio processo de fabricação [3]. O Zamac tem sido utilizado como substituto ao latão na indústria de metais sanitários, principalmente os que não possuem contato direto com água, mas enfrentam-se dificuldades de aceitação no mercado graças sua à baixa resistência à corrosão da liga revestida por galvanoplastia. Esta baixa resistência à corrosão do Zamac comparado ao latão está relacionada com o substrato e não com o revestimento [4-5]. Com base nestes preceitos, este trabalho tem por objetivo analisar a influência da microestrutura na corrosão de peças de Zamac 5 (ASTM B240-07) injetado sob pressão, sem revestimento, em névoa salina neutra, observando quais as particularidades deste processo. As amostras em estudo foram analisadas por ensaios de névoa salina, metalografia, microscopia eletrônica de varredura (MEV), microdureza Vickers e testes eletroquímicos de corrosão.

\section{MATERIAIS E MÉTODOS}

As peças em Zamac 5 foram obtidas por meio de injeção sob pressão de 125 toneladas de fechamento, com molde refrigerado de duas cavidades. As peças foram desengraxadas por 1 min com detergente alcalino a $40^{\circ} \mathrm{C}$, lavadas com água corrente, água deionizada, álcool e secas com ar frio.

Os ensaios de névoa salina foram realizados em uma câmara marca Equilam 600L, conforme procedimento descrito na norma NBR 8094 [6]. Foi utilizada solução de cloreto de sódio a 5\% (massa/volume), com pressão do saturador de ar comprimido controlada em 1,05 bar. A temperatura interna da câmara foi controlada em $35^{\circ} \mathrm{C}$ e a temperatura do saturador para formação de névoa, em $47^{\circ} \mathrm{C}$. As peças foram suspensas com um fio de nylon em ângulo de $90^{\circ}$ entre a superfície superior da peça e o bocal de saída do saturador, em ciclos de $8 \mathrm{~h}$ e 24h. Para verificar se o ângulo de disposição das peças influenciava o processo corrosivo, foi realizado um ensaio com as peças suspensas em ângulo de $45^{\circ}$ em relação ao bocal do saturador, com ciclo de $8 \mathrm{~h}$.

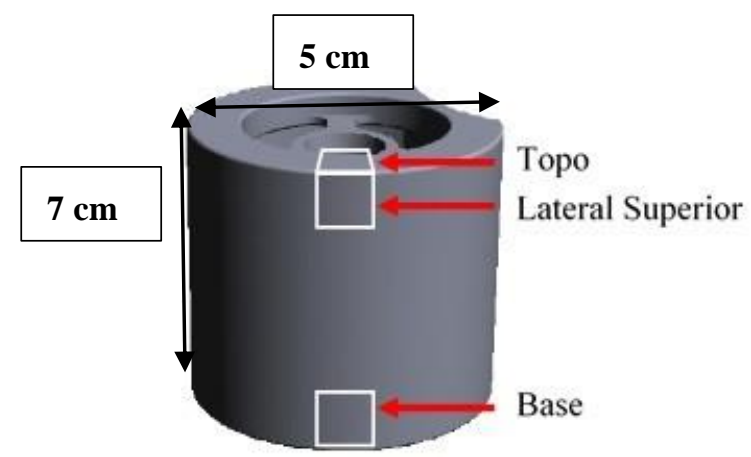

Figura 1: Geometria da peça em estudo obtida por meio de injeção sob pressão de Zamac 5 mostrando as dimensões e as regiões de Base, Lateral Superior e Topo. 
Para as análises morfológicas e microestruturais, foram retiradas amostras de aproximadamente $1 \mathrm{~cm}^{2}$ das regiões de interesse da peça de Zamac 5 injetada sob pressão nomeadas como Base, Lateral Superior e Topo, as dimensões da peça de zamac 5 são $5 \mathrm{~cm}$ de largura por $7 \mathrm{~cm}$ de altura, conforme ilustrado na Figura 1 . O ataque químico para revelação dos grãos foi realizado com Nital a $1 \%$ por 3 segundos.

As amostras foram embutidas em baquelite e lixadas com lixas de carbeto de silício de granulometria \#600, \#1200, \#2400 e \#4000, e polidas com pasta de diamante com granulometria de $1 \mu \mathrm{m}$ em politriz rotativa com o uso de água deionizada. Para a análise por microscopia eletrônica de varredura, as amostras foram metalizadas com um filme fino de ouro. O equipamento utilizado foi um Microscópio Eletrônico de Varredura modelo JEOL-JSM $6510 \mathrm{CV}$ com resolução de $129 \mathrm{eV}$. Os tamanhos de grão e defeitos de porosidade foram medidos com uso do software de tratamento de imagens Image Tool for Windows versão 3.0.

As análises de microdureza Vickers foram realizadas com uso de um microdurômetro da marca Shimadzu modelo HMV - 2T, com carga de 100 gramas e tempo aplicado da carga de 15 segundos, com indentador piramidal. Foram realizadas 10 medições em cada região.

Os ensaios eletroquímicos de corrosão foram realizados em uma célula de três eletrodos com eletrodo de referência de calomelano saturado (SCE) e contra-eletrodo de platina em eletrólito de $\mathrm{NaCl}$ a 0,6 M bem como o eletrodo de trabalho que são as amostras analisadas. As amostras apresentaram $1 \mathrm{~cm}^{2}$ de área superficial. Foram realizadas medidas de potencial de circuito aberto durante 1800 segundos e curvas de polarização potenciodinâmicas, com aplicação de intervalo de potencial de $-200 \mathrm{mV}$ até $+1000 \mathrm{mV}$ em relação ao potencial de circuito aberto, com velocidade de varredura de $1 \mathrm{mV} / \mathrm{s}$.

\section{RESULTADOS E DISCUSSÕES}

\subsection{Névoa salina}

A Figura 2 apresenta a amostra de Zamac 5 sem tratamento superficial e desengraxada, e submetida ao ensaio de névoa salina em ciclo de $8 \mathrm{~h}$ e $24 \mathrm{~h}$.

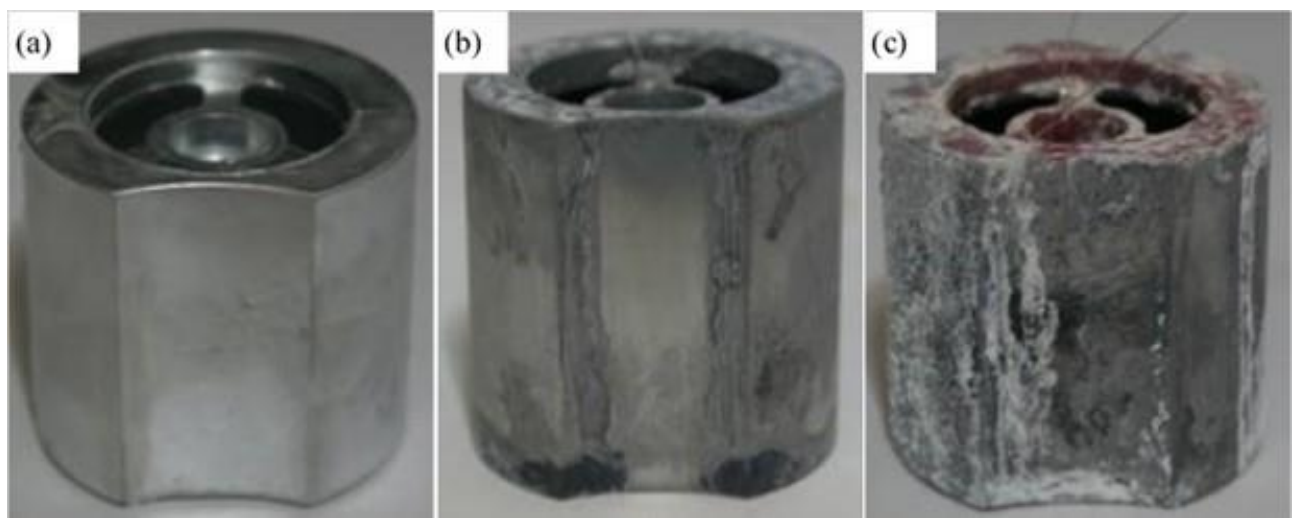

Figura 2: Zamac 5 (a) sem exposição à névoa salina e após ensaio de névoa salina, (b) ciclo de 8h e (c) ciclo de 24h.

A forte presença de corrosão branca demonstra que o comportamento da liga é semelhante ao do zinco puro [7,8]. O produto branco de corrosão é formado por sais insolúveis de zinco (como o hidróxido de zinco $\mathrm{Zn}(\mathrm{OH})_{2}$ e o carbonato de zinco $\left.-\mathrm{ZnCO}_{2}\right)$ [7,8]. É provável que também tenha ocorrido a formação de cloreto de zinco $\left(\mathrm{ZnCl}_{2}\right)$ ou hidróxicloreto de zinco $\left(\mathrm{Zn}_{5}(\mathrm{OH})_{8} \mathrm{Cl}_{2}\right)$ na superfície da peça durante a exposição à névoa salina, pela presença do íon cloreto. Como é solúvel, e devido à atmosfera úmida do ensaio, o $\mathrm{ZnCl}_{2}$ é solubilizado assim que se forma, escorrendo pela peça, formando linhas de corrosão. Estudos [9,10] mostram que o $\mathrm{Zn}_{5}(\mathrm{OH})_{8} \mathrm{Cl}_{2}$, embora insolúvel, é pouco estável, dissociando-se em compostos mais simples de zinco, como o próprio $\mathrm{ZnO}$.

A deposição de $\mathrm{NaCl}$ sobre a superfície da peça acelera o início do processo de corrosão, sendo este, um meio corrosivo forte para o zinco devido ao íon $\mathrm{Cl}^{-}$[10]. A presença do íon $\mathrm{Cl}^{-}$colabora na intensificação do processo corrosivo [9]. As amostras apresentaram regiões contendo corrosão generalizada, regiões contendo início de corrosão e regiões com pouca corrosão. Este fato pode estar associado a diferenças na matriz metálica nessas regiões, devido ao processo de fabricação das peças. Essas diferenças também podem estar relacionadas a defeitos de solidificação, tais como porosidades. As porosidades são defeitos comuns em processos de fabricação por injeção sob pressão [11] e podem ser principalmente responsáveis pela presença de corrosão por pites [12]. 
A Figura 3 mostra a peça submetida a ensaio de névoa salina com inclinação de $45^{\circ}$, com ciclo de $8 \mathrm{~h}$. Observa-se que a amostra apresenta aspecto visual semelhante ao da Figura 2 após o ensaio. Na Figura 3, observam-se regiões de corrosão intensa e regiões onde a corrosão parece não ser tão severa. Este resultado indica que o ângulo de inclinação no ensaio de névoa salina não interferiu no processo corrosivo, contribuindo para a hipótese de a corrosão estar associada à heterogeneidades da matriz metálica. Para tanto, foi realizada análise morfológica das amostras para identificar prováveis defeitos, os quais influenciaram no desempenho frente à corrosão das peças em Zamac 5.

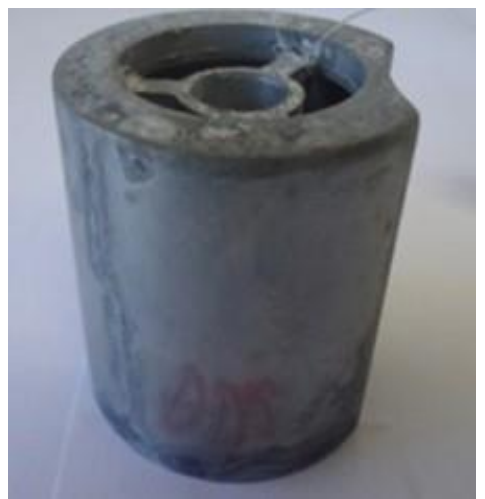

Figura 3: Fotografia da peça de Zamac 5 submetida a ensaio de névoa salina com inclinação de $45^{\circ}$, ciclo de 8 h.

\subsection{Análises morfológica e microestrutural}

A Figura 4 mostra as micrografias das regiões Base, Lateral Superior e Topo com magnificações de 100x (esquerda) e 1000x (direita).
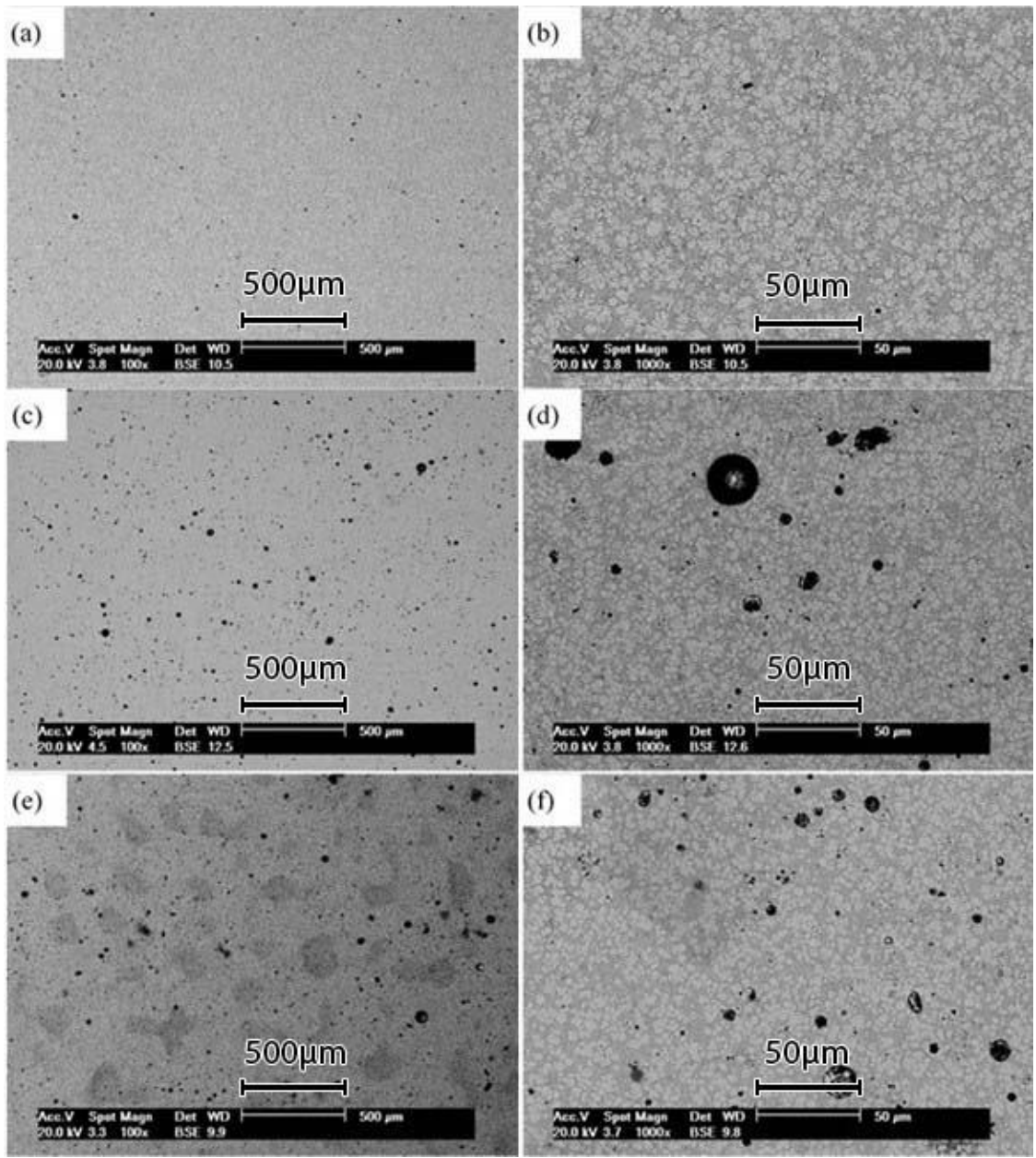

Figura 4: Micrografias das amostras de Zamac 5 das regiões Base (a) 100x, (b) 1.000x, Lateral Superior (c) 100x, (d) 1.000x e Topo (e) $100 x$ e (f) $1.000 x$. 
A presença de defeitos de porosidade é claramente observada nas micrografias da Figura 4, em que a quantidade e o diâmetro dos defeitos aumentam da região de Base para a região de Topo. Nas magnificações de 1000x é possível observar os grãos da matriz metálica juntamente com os defeitos de porosidade.

A Figura 5 mostra o detalhe de um poro localizado na região de Topo. Observa-se que o defeito tem contornos bem definidos, semelhante a uma bolha, e é aparentemente profundo. É comum que porosidades surjam em peças de injeção sob pressão, mostrando-se como orifícios aprisionados no interior das paredes da peça.

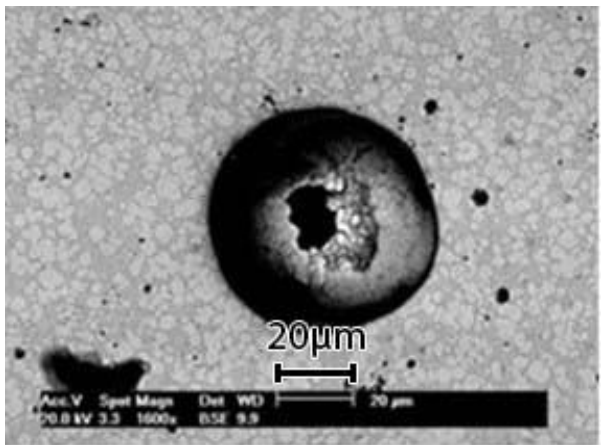

Figura 5: Detalhe de porosidade na região do Topo.

A porosidade, também chamada de porosidade gasosa, é gerada por gases, geralmente ar ou vapor de água, aprisionado no interior da matriz. $\mathrm{O}$ ar aprisionado nas cavidades do molde, quando comprimido pela massa fluida, não consegue escapar totalmente para as bolsas de ar (massalotes). Já o vapor de água é gerado quando o metal fluido encontra água pelo trajeto da injeção. A água, contida nos desmoldantes ou vinda de vazamentos dos fluidos de refrigeração, se expande proporcionando pequenas explosões, que formam os poros [13]. Gases gerados pela oxidação dos elementos de liga também podem ficar aprisionados na matriz metálica, formando o defeito da porosidade. O próprio projeto do molde pode ser determinante para a presença de porosidade. Se o molde permite um escoamento em fluxo mais laminar do que turbulento da massa fluida, a presença de porosidades pode ser minimizada. Contudo, a geometria do molde depende da complexidade da geometria da peça. Peças complexas normalmente requerem velocidades altas de injeção para garantir um preenchimento completo do molde [14].

A Figura 6 mostra as micrografias das regiões de Base, Lateral Superior e Topo com magnificação de $10.000 \mathrm{x}$
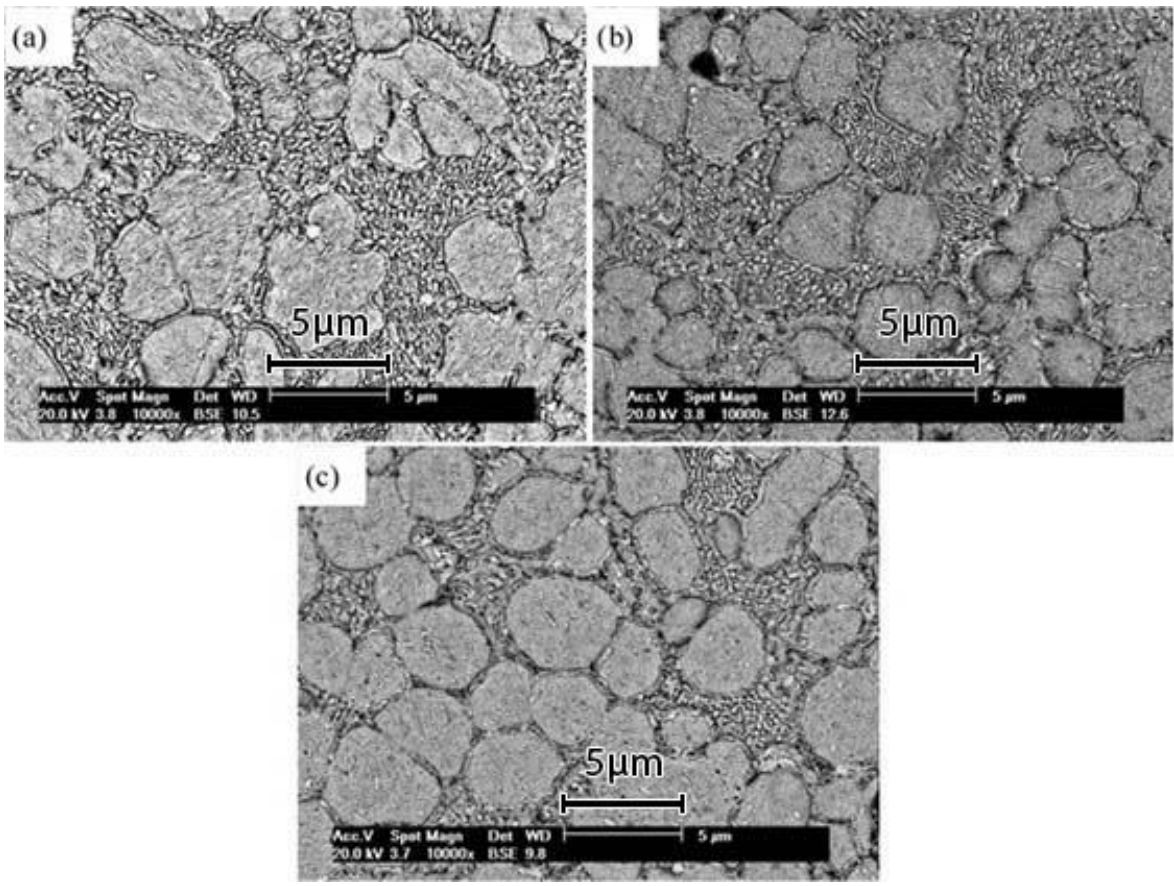

Figura 6: Micrografias das amostras de Zamac 5 injetado sob pressão das regiões de (a) Base, (b) Lateral Superior e (c) Topo. Magnificação $10.000 x$. 
Observa-se na micrografia da Base, que a região apresenta grãos maiores em relação aos observados nas micrografias da Lateral Superior e Topo, respectivamente. Além disso, observa-se que a quantidade de grãos formados na Base é menor do que nas regiões de Lateral Superior e Topo. Os grãos formados em todas as regiões têm formato celular, mais arredondados nas regiões de Lateral Superior e Topo. O tamanho dos grãos de cada região está mostrado na Tabela 1.

Tabela 1: Tamanho de grãos das regiões de Base, Lateral Superior e Topo.

\begin{tabular}{l|c}
\hline REGIÃO & TAMANHO MÉDIO DO GRÃO $(\boldsymbol{\mu m})$ \\
\hline Base & $4,08 \pm 0,48$ \\
\hline Lateral Superior & $3,18 \pm 0,16$ \\
\hline Topo & $3,69 \pm 0,31$ \\
\hline
\end{tabular}

A Tabela 1 não apresenta diferença significativa de tamanho de grão entre as regiões, embora a região de Base apresente uma média de tamanho de grão maior, porém com pouca regularidade, considerando o desvio padrão associado. Observando esse resultado e a formação de eutético na região de Base, pode-se inferir que isto indica que o processo de resfriamento após a injeção das peças foi mais lento nessa região.

Segundo Gentil [15], a diferença de tamanho de grão pode gerar comportamentos diferenciados em relação à resistência à corrosão, sendo que grãos finos de uma determinada matriz metálica apresentam maior energia interna e tendem a ser mais afetados pela corrosão do que grãos maiores. Observa-se, no entanto, que a região Base (Figura 1 e Figura 2), que contém grãos maiores (Figura 6), foi a que apresentou melhor comportamento frente à corrosão e não a região de Topo, que apresenta grãos menores. Atribui-se o fato à presença de porosidades na região de Topo, ausentes ou em menor quantidade e tamanho na região de Base.

Na Figura 6, observa-se que os grãos estão envoltos em uma matriz lamelar. Essa característica é própria das ligas hipoeutéticas resfriadas em condições fora do equilíbrio, em que se espera que o microconstituinte primário (no caso, o zinco - fase $\eta$ ) encontre-se zonado em relação a uma matriz de composição eutética/eutetóide. A fase eutética forma-se por difusão dos átomos dos constituintes primários, em camadas alternadas de distâncias relativamente curtas, formando lamelas [16]. Portanto, o aspecto visual da microestrutura mostrado nas micrografias das três regiões está de acordo com o esperado.

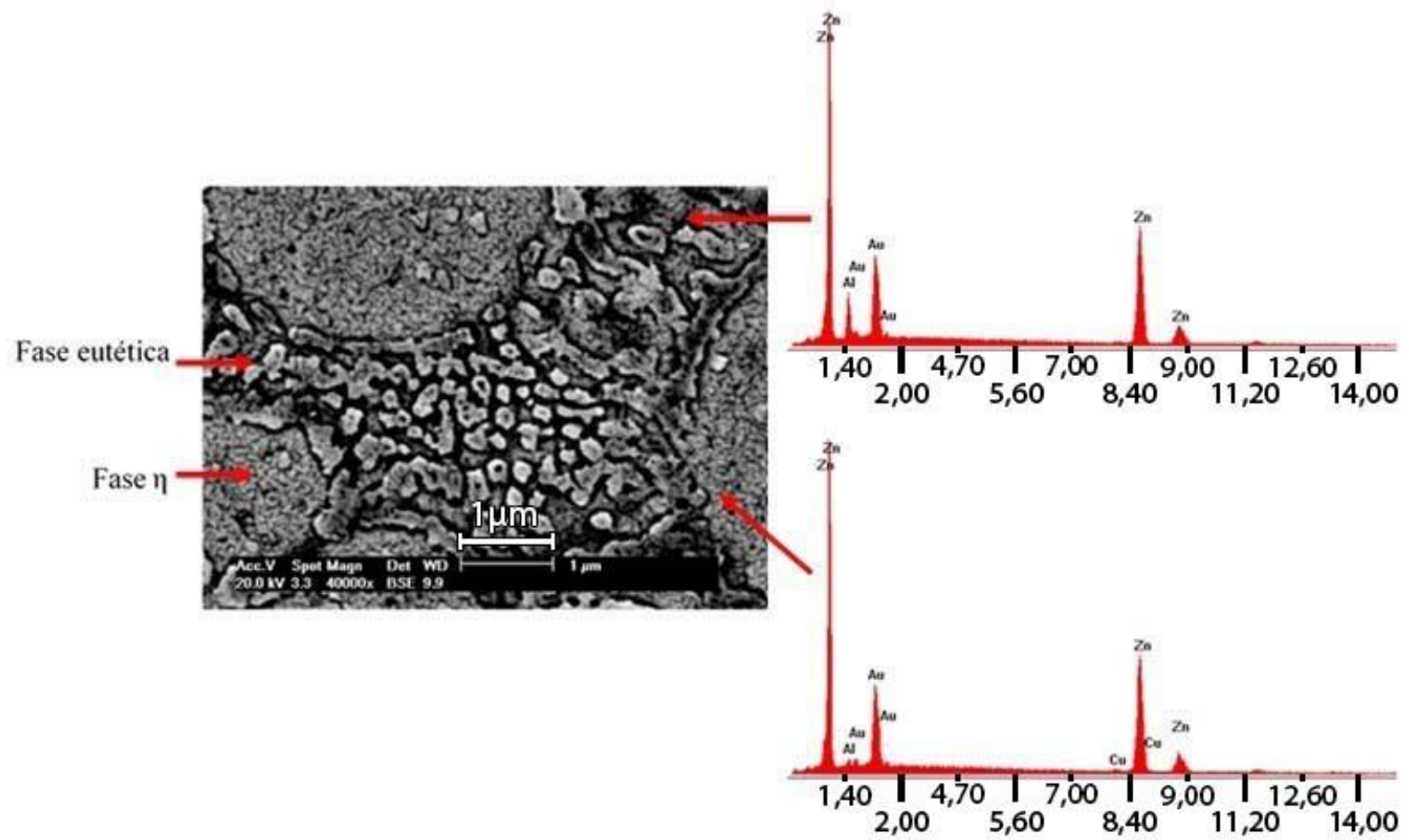

Figura 7: Micrografia da região de Topo e espectros de EDS das fases eutética e $\eta$. 
Através do diagrama de fases da liga $\mathrm{Zn}-\mathrm{Al}$ [16], o ponto eutético é formado pela fase $\eta+\beta$, que inicia sua formação em $382^{\circ} \mathrm{C}$. Como a liga encontra-se em temperatura ambiente, a composição do eutético passa por uma transição eutetóide que se inicia a $275^{\circ} \mathrm{C}$, onde a constituição da fase lamelar muda para $\eta+\alpha$. Essa última fase é também conhecida como eutético secundário [16,17]. Para identificar a composição das fases presentes e confirmar os resultados esperados, foram realizados ensaios de espectroscopia de energia dispersiva (EDS).

A microanálise por EDS mostra uma estimativa da composição elementar de pontos ou região da amostra. A Figura 7 mostra a micrografia da região de Topo, com identificação das fases eutética e $\eta$, incluindo os respectivos espectros de EDS dessas fases, cujos resultados estão apresentados na Tabela 2.

Tabela 2: Percentual em massa dos elementos químicos das fases eutética e $\eta$ baseada nos espectros de EDS da Figura 7.

\begin{tabular}{c|c|c}
\hline ELEMENTO & FASE EUTÉTICA (\% EM MASSA) & FASE $\eta$ (\% EM MASSA) \\
\hline $\mathrm{Al}$ & 11,68 & 2,08 \\
\hline $\mathrm{Au}$ & 0 & 29,12 \\
\hline $\mathrm{Cu}$ & 0 & 1,26 \\
\hline $\mathrm{Zn}$ & 88,32 & 67,54 \\
\hline
\end{tabular}

A composição teórica do eutético é de 5\% de alumínio e 95\% de zinco [16]. Não há outros elementos de liga presentes, mostrando que o eutético segue a composição esperada para sua formação, mesmo que os valores encontrados (considerando as limitações inerentes à metodologia utilizada) estejam diferentes dos limites estabelecidos pela literatura para a liga. A presença de um percentual maior de alumínio do que a composição teórica do eutético evidencia que a fase eutética presente é a secundária (eutetóide). Estruturas semelhantes podem ser encontradas na literatura [19], para a caracterização da liga eutetóide Zn-22\%Al e relação entre a taxa de solidificação e o envelhecimento. Neste caso, observa-se a formação da fase $\eta$, rica em zinco, bem como a fase lamelar de eutético secundário (eutetóide) $\eta+\alpha$. Como as condições de resfriamento variaram, verificou também que as estruturas lamelares eutética $\eta+\beta$ e eutetóide $\eta+\alpha$ podem coexistir na mesma matriz, tendo apenas variações na espessura das lamelas. A fase $\beta$ é formada por percentual maior de zinco em relação à fase $\alpha$, que é rica em alumínio. Já os resultados da fase $\eta$ mostram que o constituinte predominante é o zinco, como esperado. O alumínio e o cobre estão presentes, em pequenas quantidades, o que também corresponde ao resultado previsto, pois a concentração desses elementos de liga no Zamac 5 é baixa. A presença de ouro no espectro é devido à preparação da superfície para a realização da análise. Não se observa no espectro a presença de magnésio, elemento de liga presente na composição química do Zamac 5, porém esta ausência pode ser atribuída à sua pequena concentração na liga (entre 0,03 e $0,06 \%$ ) [16].

\subsection{Análise de microdureza}

A dureza de um material depende de sua macro e microestrutura, das forças de ligação entre os átomos e da resistência mecânica desse material. A Tabela 3 mostra a microdureza Vickers das regiões de Base e Topo.

Tabela 3: Valores de microdureza Vickers das regiões de Base e Topo de Zamac 5 injetado sob pressão.

\begin{tabular}{c|c}
\hline REGIÃO & MICRODUREZA \\
\hline Base & $116 \mathrm{HV} \pm 5$ \\
\hline Topo & $97 \mathrm{HV} \pm 2$ \\
\hline
\end{tabular}

A Tabela 3 mostra uma diferença de microdureza de cerca de $18 \%$ entre as regiões de Topo e Base, com maior valor de microdureza para região de Base $(116$ HV) em comparação à região de Topo $(97$ HV). Esses resultados estão de acordo com os resultados de $\mathrm{MEV}$, pois a região com maior quantidade de defeitos é também a que apresenta menor microdureza. Na literatura [19], a microdureza medida para o Zamac 5 fundido por gravidade oscilou entre 80 e $100 \mathrm{HV}$, o que foi atribuído à quantidade de eutético formado em função da temperatura de solidificação utilizada. No entanto, no presente trabalho, a menor microdureza observada (na região de Topo, 97 HV) parece decorrer do fato de que as imperfeições da matriz metálica (poros) não impõem resistência à entrada do penetrador, pois as mesmas são vazios dentro da massa sólida. Para exemplificar melhor, a Figura 8 mostra a micrografia da região de indentação da amostra de Base utilizada para análise de dureza. Observa-se nessa região uma matriz homogênea, livre de defeitos, o que está de acordo com a maior microdureza medida. 


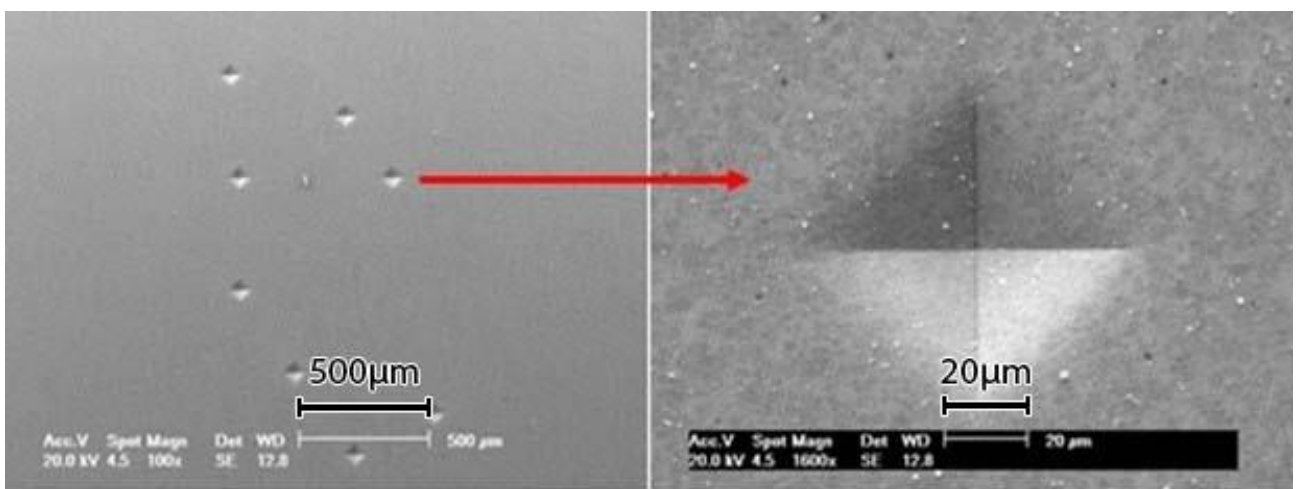

Figura 8: Micrografias da amostra da região de Base com a impressão do indentador.

\subsection{Análises eletroquímicas}

\subsubsection{Potencial de circuito aberto}

Os ensaios de potencial de circuito aberto de amostras das regiões de Base, Lateral Superior e Topo em solução de $\mathrm{NaCl}$ estão mostrados nos gráficos da Figura 9.

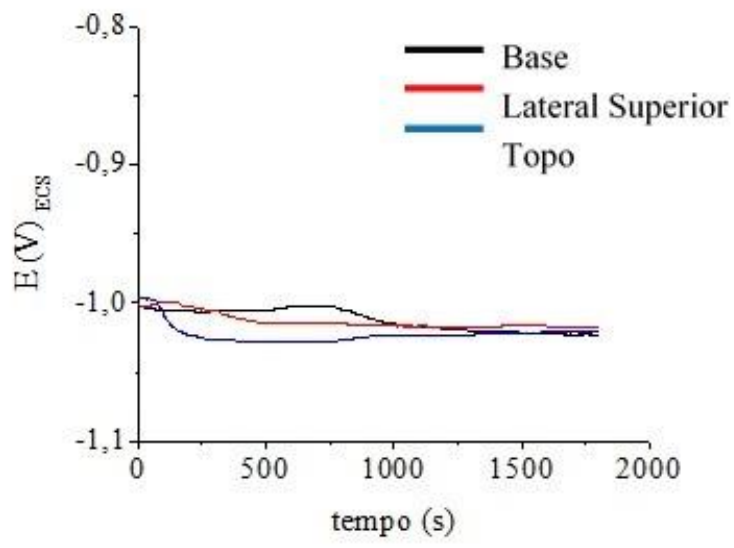

Figura 9: Potencial de circuito aberto de regiões de Base, Lateral Superior e Topo de Zamac 5 injetado sob pressão. Ensaio realizado em $0,6 \mathrm{M} \mathrm{NaCl}, \mathrm{pH} 5,5$.

Observa-se que no meio utilizado $(\mathrm{NaCl}$ 0,6 M), apesar de algumas regiões apresentarem maior incidência de defeitos do que outras, não há variação significativa entre as amostras, pelo menos dentro do tempo de ensaio estabelecido. Manteve-se um potencial praticamente estável por aproximadamente 1800 segundos, oscilando entre -1,000 e -1,025 V. O tempo de imersão da amostra durante a medida e a agressividade do eletrólito podem ter influenciado no resultado obtido. Observa-se, então, que os valores encontrados para Zamac 5 evidenciam que o comportamento da liga tende a assemelhar-se ao do metal puro [21-23]. Isso já era esperado, uma vez que a liga é formada basicamente por zinco. As adições de alumínio, cobre e magnésio, nas concentrações presentes na liga, não influenciam significativamente o comportamento eletroquímico do Zamac 5 no potencial de circuito aberto dentro das condições de ensaio. 


\subsubsection{Medidas eletroquímicas de polarização potenciodinâmica}

A Figura 10 mostra as curvas de polarização potenciodinâmica das amostras de Base, Lateral Superior e Topo.

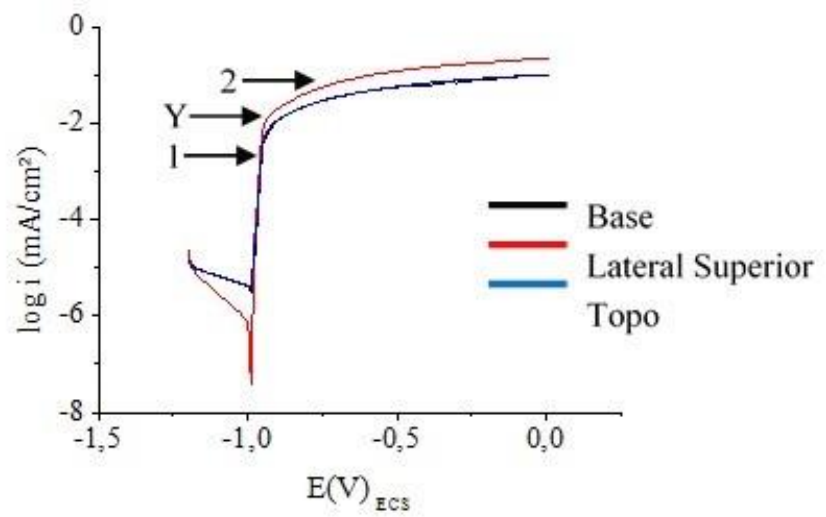

Figura 10: Curvas de polarização potenciodinâmica das regiões de Base, Lateral Superior e Topo em NaCl 0,6M, pH 5,5. 1 Ponto final da dissolução do metal. 2 - Ponto de estabilidade (início da densidade corrente limite). Y - Ponto de interrupção para visualização ao MEV.

Considerando que a corrosão do Zamac 5 assemelha-se ao processo desenvolvido pelo zinco [7, 22], o comportamento da corrosão do zinco em eletrólito de $\mathrm{NaCl}$ desenvolve-se em duas reações parciais [24]. Essas equações, de redução e de oxidação, são descritas nos itens a seguir.

a) Reação catódica (1), correspondente à redução do oxigênio ocasionando incremento de pH:

$$
\mathrm{O}_{2(\mathrm{~g})}+2 \mathrm{H}_{2} \mathrm{O}_{(\mathrm{l})}+4 \mathrm{e}^{-} \rightarrow 4 \mathrm{OH}_{(\mathrm{aq})}^{-}
$$

b) Reação anódica (2), que envolve a dissolução do zinco e perda de massa da matriz metálica:

$$
\mathrm{Zn}_{(\mathrm{s})} \rightarrow \mathrm{Zn}_{(\mathrm{aq})}{ }^{2+}+2 \mathrm{e}^{-}
$$

As curvas desenvolvidas nos ensaios de polarização da região de Base, Lateral Superior e Topo sugerem comportamento similar ao do zinco puro $[4,25,26]$. De acordo com a Figura 10, as curvas anódicas para as três regiões analisadas mostram regiões distintas; uma do potencial de corrosão (Ecorr) até o ponto 1, onde o principal mecanismo envolvido é o de dissolução do metal, juntamente com uma evidenciada polarização por concentração. Do ponto 1 até o ponto 2, a dissolução continua ocorrendo, porém já inicia a formação de uma camada de produto de corrosão sobre a superfície. Por fim, a partir do ponto 2, a curva mostra o aumento do potencial associado a uma estabilidade da densidade de corrente, chegando à densidade de corrente limite anódica. Observa que esse comportamento mostra que a camada formada não é totalmente passiva, mas sim pseudo-passiva [21]. No primeiro caso, se a camada fosse passiva por completo, se verificaria o decaimento da densidade de corrente, o que não ocorre, concordando com a hipótese de formação do hidróxi-cloreto de zinco, hidróxi-sal instável que permite a formação de densidade de corrente limite anódica. As curvas da Figura 10 também sugerem que a liga é suscetível à corrosão por pite [4,8], o que se relaciona à hipótese de a corrosão na liga iniciar-se por pite verificada nos ensaios de névoa salina realizados neste estudo. O pite parece evoluir, então, para corrosão generalizada em função do tempo de exposição à névoa salina [8,27,28]. A velocidade e o intervalo de varredura utilizados neste estudo, contudo, não permitem uma conclusão a respeito destas considerações.

Além disso, observa-se um aumento abrupto da corrente logo no início da curva anódica, o que sugere o surgimento de corrosão generalizada, como evidenciado pelos ensaios de corrosão em névoa salina, embora a literatura [8] mostre que também possa indicar uma dissolução localizada da liga, provavelmente como pite. Parece que na amostra de Topo, essa dissolução é mais intensa que nas demais amostras, pois ela desenvolve pico maior de densidade de corrente até o ponto onde a corrente começa a estabilizar.

Como as curvas de polarização apresentaram aumento abrupto da corrente, as curvas foram refeitas e interrompidas antes da passivação, no ponto Y do gráfico apresentado na Figura 10, para verificar o início da corrosão. A Figura 11 mostra as regiões de Base, Lateral Superior e Topo analisadas em microscopia eletrônica de varredura, no início da corrosão. 


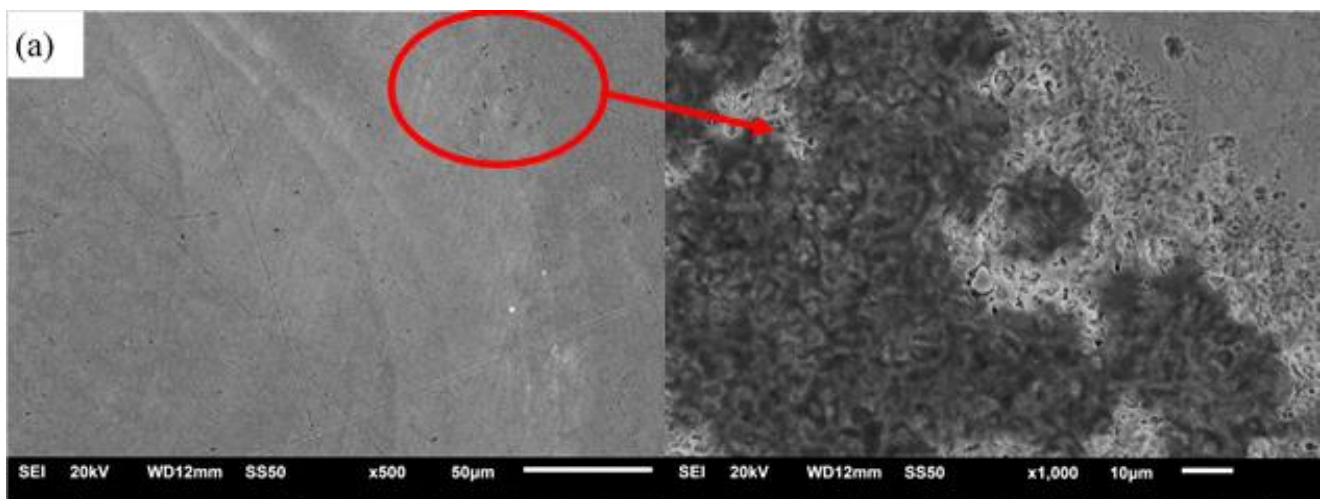

(b)
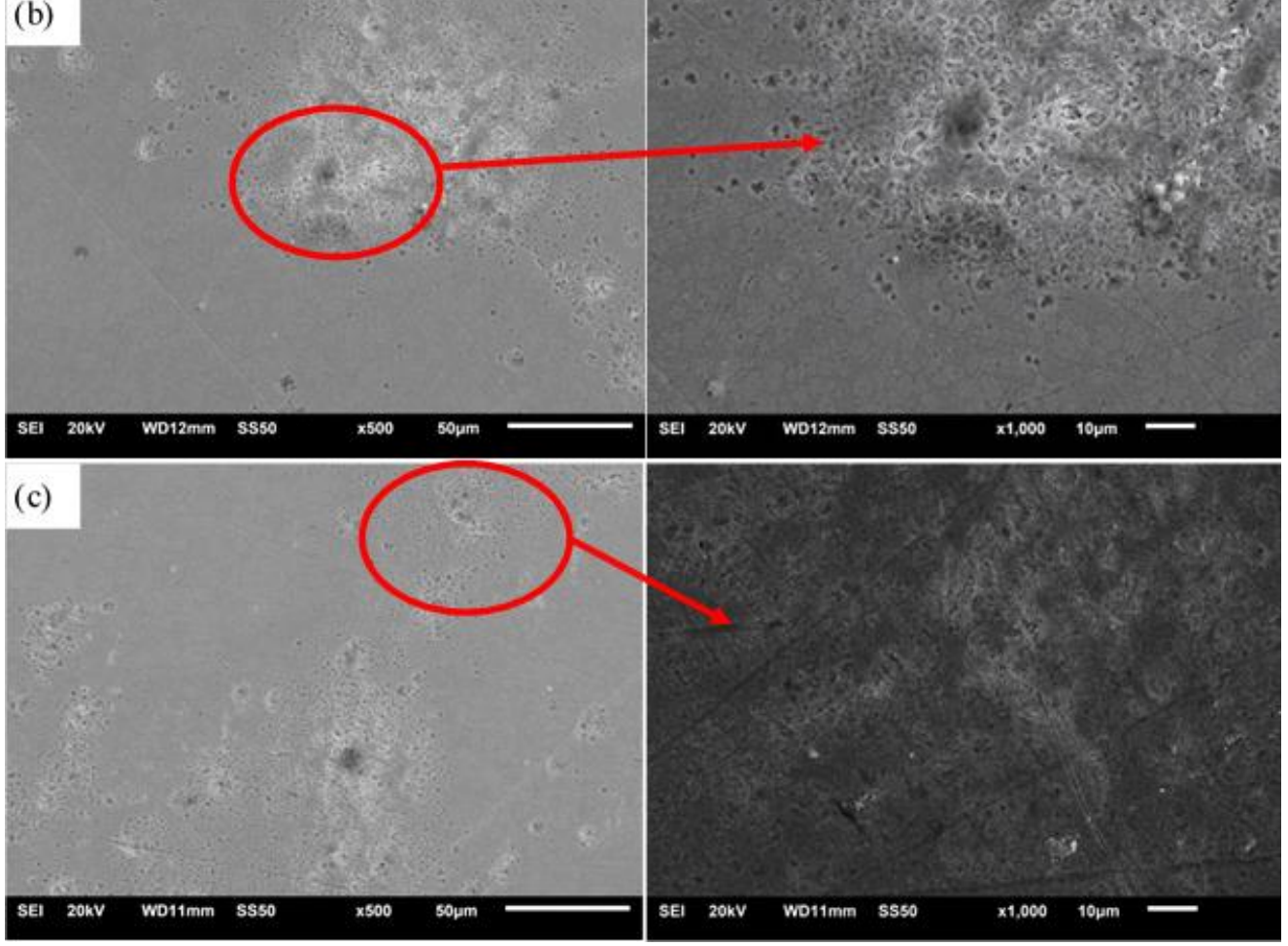

Figura 11: Micrografias das amostras de Zamac 5 injetado sob pressão, após o ensaio de polarização interrompido no ponto Y da Figura 10. (a) de (a) Base, (b) Lateral Superior e (c) Topo.

Na Figura 11, todas as áreas de aparência esbranquiçada denotam a presença do início do produto de corrosão. Não se evidenciaram modificações significativas entre as amostras, mostrando que o processo eletroquímico nas três regiões parece ser semelhante. Com isso, observando também as curvas de polarização e o resultado de potencial de circuito aberto (Figura 9), pode-se evidenciar que o comportamento eletroquímico da liga é semelhante nas regiões analisadas. Isso pode ser explicado pois a matriz metálica é a mesma, e as porosidades que influenciam no ataque por névoa salina parecem não contribuir no processo eletroquímico.

\section{CONCLUSÕES}

A análise dos resultados experimentais em amostras de Zamac 5 injetado sob pressão permite evidenciar que a corrosão por exposição à névoa salina do material é semelhante à corrosão do zinco, com formação intensa de produtos brancos de corrosão. A corrosão parece iniciar com a formação de pite em locais preferenciais das peças, evoluindo para corrosão generalizada. As análises por microscopia eletrônica de varredura mostraram diferenças na microestrutura do metal, contribuindo para a formação de porosidades. Por último, os ensaios de polarização potenciodinâmica mostraram que a presença de defeitos parece não influenciar de forma significativa as propriedades eletroquímicas da liga nas diferentes regiões analisadas. 


\section{AGRADECIMENTOS}

Os autores deste trabalho agradecem à CAPES, CNPq, FAPERGS, Laboratório de Estudos Avançados em Materiais da Universidade Feevale e ao INCT-INES - Instituto Nacional de Engenharia de Superfície.

\section{BIBLIOGRAFIA}

[1] FAN, C.H., CHEN, Z. H., HE, W.Q., et al., "Effects of the casting temperature on microestructure and mechanical properties of the squeeze cast Al-Zn-Mg-Cu alloy", Journal of Alloys and Compounds, v. 504, n. 2, pp. L42-L45, 2010.

[2] RUN-XIA, L., LI, R., BAI, Y. "Effect of specific pressure on microstructure and mechanical properties of squeeze casting ZA27 alloy", Transactions of Nonferrous Metals Society of China, v. 20, n. 1, pp. 59-63, 2009.

[3] BOSS, A., "Processo de cromação do Zamac: Discussão, inovaçães, tendências e otimização do processo", Revista Tratamento de Superficies, n. 180, pp.28-37, 2013. Disponível em: <http://www.abts.org.br/revistavisualizar.asp?id=3\&edicao=180>. Acesso em: 02 nov. 2018.

[4] XIA, W., DIVYARAJ, D. B., GAUTAM, G., et al., "Impact of anode substrates on electrodeposited zinc over cycling in zinc-anode rechargeable alkaline batteries", Electrochimica Acta, v. 212, pp. 603-613, 2016.

[5] JAIN, R., PITCHUMANI, R., "Fabrication and characterization of zinc-based superhydrophobic coatings", Surface \& Coatings Technology, v. 337, pp. 223-231, 2018.

[6] ASSOCIAÇÃO BRASILEIRA DE NORMAS TÉCNICAS. NBR 8094: Material metálico revestido e nãorevestido - corrosão por exposição à névoa salina, 1983.

[7] SCHWEITZER, P. A. Fundamentals of Metallic Corrosion: Atmospheric and Media Corrosion of Metals, 2 ed. New York, Crc, 2007.

[8] MENGA, Y., LIUA, L., ZHANGB, D., et al., "Initial formation of corrosion products on pure zinc in saline solution", Bioactive Materials, 2018. Elsevier BV. http://dx.doi.org/10.1016/j.bioactmat.2018.08.003. Disponível em: 〈https://www.sciencedirect.com/science/article/pii/S2452199X18300240>. Acesso em: 02 nov. 2018.

[9] AAL, E., ABD El., "On the pitting corrosion currents of zinc by chloride anions", Corrosion Science, v. 46, n. 1, pp.37-49, 2004.

[10] EIN-ELI, Y., AUINAT, M., STAROSVETSKY, D., "Eletrochemical and surface studies of zinc in alkaline solutions containing organic corrosion inhibitors", Journal of Powder Sources, v. 114, n.2 pp.330-337, 2002.

[11] VIJIAN, P., ARUNACHALAM, V. P., "Optimization of squeeze cast parameters of LM6 aluminium alloy for surface roughness using Taguchi Method", Journal Of Materials Processing Technology, v. 180, n. 1-3, pp.161-166, 2006.

[12] NEUFELD, A. K., COLE, I. S., BOND, A. M., et al., "The initiation mechanism of corrosion of zinc by sodium chloride particle deposition”, Corrosion Science, v. 44, n.3, pp. 555-572, 2001.

[13] CHIAVERINI, V., Tecnologia Mecânica, 2.ed. São Paulo, Makron Books, 1986.

[14] KNIGHT, B., COWELL, D., PREDDY, K., "An Object-oriented Support Tool for the Design of Casting Procedures", Engineering Applications of Artificial Intelligence, v. 8, n. 5, pp. 561-567, 1995.

[15] GENTIL, V. Corrosão. 3. ed. Rio de Janeiro, Ltc, 1996. 345 p.

[16] OKAMOTO, H., SCHLESINGER, M. E., MUELLER, E. M., ASM Handbook . v. 3, Alloy Phase Diagrams. 10 ed., Vev, ASTM International, 2016.

[17] COSTA, E. M., COSTA, C. E., VECCHIA, F. V., et al., "Study of the influence of copper and magnesium additions on the microstructure formation of $\mathrm{Zn}-\mathrm{Al}$ hypoeutectic alloys". Journal of Alloys and Compounds, $\mathrm{v}$. 488, n. 1, pp.89-99, 2009.

[18] MAGER, B., STELLA, S., DEDAVID, B A., et al., "Influência da taxa de solidificação na morfologia das fases da liga eutetóide Zn-22\%Al”, Revista Escola de Minas, v. 62, n. 2, 2009.

[19] OSÓRIO, W. R., SPINELLI, J. E., FREIRE, C. M. A., et al., "Efeitos das diferentes morfologias estruturais e tamanho de grão na resistência à corrosão de amostras de zinco e alumínio puros", Revista Matéria, v. 10, n. 3, pp. $428-436,2005$.

[20] MARCOLIN, P., LONGHI, M., ZINI, L. P., et al., "Effects of the Casting Temperature in the Leakage of Zamak 5", Materials Science Forum, v. 899, pp.458-462, 2017.

[21] MOUANGA, M., BERÇOT, P., RAUCH, J. Y., "Comparison of corrosion behaviour of zinc in $\mathrm{NaCl}$ and in $\mathrm{NaOH}$ solutions. Part I: Corrosion layer characterization", Corrosion Science, v. 52, n. 12, pp.3984-3992, 2010. 
[22] LI, Q., ZHANG, Q., AN, M., "Enhanced corrosion and wear resistance of AZ31 magnesium alloy in simulated body fluid via electrodeposition of nanocrystalline zinc. Materialia, 2018. Elsevier BV. http://dx.doi.org/10.1016/j.mtla.2018.09.038. Disponível em: <https://www.sciencedirect.com/science/article/pii/S2589152918301674?via\%3Dihub>. Acesso em: 02 nov. 2018.

[23] SOUZA, M.E.P., ARIZA, E., BALLESTER, M., et al., "Silicone resin to improve corrosion resistance of Zn and ZnFe coated steel”, Revista Matéria, v. 11, n. 1, pp.16-23, 2006.

[24] MANOV, S., LAMAZOUÈRE, A. M., ARIÈS, L., "Electrochemical study of the corrosion behaviour of zinc treated with a new organic chelating inhibitor", Corrosion Science, v.42, n.7, pp. 1235-1248, 2000.

[25] OSÓRIO, W. R., SPINELLI, J.E., FREIRE, C.M.A., et al., "Efeito da Macro e Micromorfologia Estruturais na Resistência à Corrosão de Amostras de Zn Puro e da Liga Zn-4\%Al”. Revista Materia, v. 10, n. 3, pp.428436, 2005.

[26] MOSTAED, E., SIKORA, M. J., DRELICH, J. W., et al., "Zinc-based alloys for degradable vascular stent applications", Acta Biomaterialia, v. 71, pp.1-23, 2018.

[27] AAL, E. E. A. E. A., "Effect of $\mathrm{Cl}^{-}$anions on zinc passivity in borate solution", Corrosion Science, v. 42, n. 1 , pp.1-16, 2000.

[28] AAL, E. E. A. E. A., "Limits determination of toleration of aggressive anions by a certain passivator on zinc surface", Corrosion Science, v. 50, n. 1, pp.47-54, 2008.

\section{ORCID}

Luciane Thaís Fuhr

Ana Caroline Viero Bianchin

Felipe Dalla Vecchia

Fernando Dal Pont Morisso

Ângela Beatrice Dewes Moura

Ricardo Martins de Martins

Carlos Leonardo Pandolfo Carone

Sandra Raquel Kunst

Cláudia Trindade Oliveira https://orcid.org/0000-0001-8053-3613

https://orcid.org/0000-0002-3389-2469

http://orcid.org/0000-0002-0272-4382

http://orcid.org/0000-0002-9653-9857

https://orcid.org/0000-0001-7200-1668

http://orcid.org/0000-0002-0045-2897

http://orcid.org/0000-0002-4084-4502

http://orcid.org/0000-0002-8060-3981

https://orcid.org/0000-0002-4472-5359 